\title{
EXTRACCIÓN DE PIGMENTOS Y MODOS DE PRODUCCIÓN RITUAL EN LA CULTURA NASCA: IMPLICACIONES PARA LA SECUENCIA OCUPACIONAL DE Mina PRIMAVERA
}

\author{
Hendrik Van Gijseghem ${ }^{2}$ \\ Kevin J. Vaughn ${ }^{\mathrm{b}}$ \\ Verity H. Whalen ${ }^{\mathrm{C}}$ \\ Moises Linares Grados ${ }^{\mathrm{d}}$
}

\begin{abstract}
Resumen
Presentamos resultados de investigaciones realizadas en un sitio minero del área Nasca. En particular, en el sitio de Mina Primavera, valle de Ingenio, una fuente de hematita (óxido de hierro) cuya explotación se remonta a los primeros siglos del primer milenio d.C., hemos encontrado en contexto estratigráfico testigos de las primeras épocas de extracción, correspondientes a material cerámico conocido como Nasca 1, o Nasca Inicial. Estos descubrimientos ponen de relieve las innovaciones técnicas asociadas con el desarrollo de pintura precocción como vehiculo para la iconografia, y un nuevo culto que se estaba elaborando en Cahuachi. Además, reconocemos que existía una variedad de otros usos de las hematita en Nasca Temprano, incluyendo su empleo como ofrendas, asi como pintura de paredes en contextos monumentales. En efecto, la extracción de pigmentos desde Mina Primavera se aceleró notablemente en la siguiente época de Nasca Temprano, acompañada por prácticas rituales, y al parecer cesa con el abandono de Cabuachi como centro ceremonial, después de lo cual el espacio de la mina aparentemente se convirtió en un espacio sagrado análogo a las estructuras que se conocen como huaca.
\end{abstract}

Palabras claves: nasca, mineria, hematita, ritual

\section{Abstract}

PIGMENT EXTRACTION AND RITUAL MODES OF PRODUCTION IN THE NASCA CULTURE: IMPLICATIONS FOR THE OCCUPATIONAL SEQUENCE AT MINA PRIMAVERA

We present the results of excavations carried out in an ancient mining site in the Nasca region. Mina Primavera, near the Ingenio valley, is a source of hematite (iron oxide) that was exploited during the first four centuries $A D$. We have encountered stratigraphic contexts y radiocarbon dates that indicate that the first episodes of exploitation correspond

a Département d'anthropologie, Université de Montréal

Correo electrónico: h.van.gijseghem@gmail.com

${ }^{\mathrm{b}}$ Department of Anthropology, University of California, Riverside

Correo electrónico: kevin.vaughn@ucr.edu

c Dawson College

Correo electrónico: verity.whalen@gmail.com

${ }^{\mathrm{d}}$ Arqueocare

Correo electrónico: arqueocare@gmail.com 
to ceramic material we know as Nasca 1 or Initial Nasca. These discoveries highlight the technological innovations associated with the development of pre-fire ceramic paints as a medium for iconography in the context of a new cult being elaborated at Cahuachi at that time. Moreover, hematite was certainly extracted for other purposes than ceramic paint manufacture, including its use in offerings y the colorings of murals y temple facades. The extraction of minerals from Mina Primavera accelerated during Early Nasca, corresponding to the development of new ritual practices, y apparently ceased with the abandonment of Cahuachi as a ceremonial center, after which the cavity inside the mine may have become (or remained) sacred as something analogous to a huaca.

Keywords: Nasca, mining, hematite, ritual

\section{Introducción}

La transición entre las culturas precolombinas de Paracas y Nasca ha sido tradicionalmente identificada con el desarrollo de pigmentos aplicados antes de la cocción en artefactos cerámicos. Igualmente, dicho desarrollo ha sido frecuentemente descrito como una distinción arbitraria en una secuencia histórica, que de otro modo se ve caracterizada por continuidad (Menzel, Rowe y Dawson 1964; Silverman 2002). No obstante, se debe reconocer que este período de transición representó cambios sociales que transformaron profundamente las existencias religiosas y políticas entre las poblaciones de la Costa Sur (Van Gijseghem y Vaughn 2008). Dichos cambios se vieron materializados en la fundación y eventual prominencia del centro ceremonial y ritual de Cahuachi. Aunque se da por entendido que a la cultura Paracas tradicional precede e informa al período conocido como Proto Nasca o Nasca Inicial, debe mencionarse también que las innovaciones en prácticas culturales, sociales y religiosas indican al mismo tiempo una disyunción y la formación de la cultura de la primera parte del Período Intermedio Temprano, que hoy en día conocemos como Nasca Temprano (Vaughn y Van Gijseghem 2007; Van Gijseghem 2006, 2013).

El cambio más ampliamente reconocido proveniente de aquel período es el remplazo de pigmentos compuestos de resina (aplicada después de la cocción), por pinturas aplicadas antes de la cocción, hechas a su vez en base a minerales. Durante los inicios del período Proto Nasca, se observa el desarrollo y la aplicación de capas ligeras de tintes crema y rojo de varias calidades en recipientes cocidos a alta temperatura y de espesor delgado. Rápidamente esta nueva tecnología incorporó la gran variedad de colores por los que hoy se conoce la cerámica nasca. Es entonces de importancia notar que dichos desarrollos parecen coincidir con el establecimiento de Cahuachi como centro ceremonial regional (Vaughn y Van Gijseghem 2007; Kanther y Vaughn 2012; Orefici 2011), y que, con ellos, la cerámica parece también haber remplazado a los textiles como el medio principal de transmisión de la ideología religiosa (Proulx 2006). Este nuevo vehículo en conjunción con las innovaciones tecnológicas previamente mencionadas dotó a los líderes de Cahuachi de una poderosa manera de materializar y diseminar nuevas concepciones del cosmos. La cerámica, producida en cantidades extremadamente grandes, era llevada en el contexto de peregrinajes desde Cahuachi hasta pueblos periféricos (Vaughn 2004, 2005; Vaughn y Neff 2004; Kantner y Vaughn 2012). Estos cambios también coinciden con mejoras graduales y mayor predictibilidad interanual en las condiciones climáticas (Eitel et al. 2005; Beresford-Jones et al. 2009; Kantner y Vaughn 2012).

Es así que nuevas pautas ceremoniales requirieron nuevas prácticas de producción, que a su vez modificaron eminentemente la economía política de las sociedades de la Costa Sur a principios del primer milenio a.C. De manera discursiva, el desarrollo de nuevas tecnologías de producción de cerámica, al igual que el aspecto llamativo de las mismas, en conjunción con su amplia circulación también facilitaron el surgimiento del «culto Cahuachi» (Vaughn y Van Gijseghem 2007). Katherine Spielmann (2002: 203), mantiene que en varias sociedades pre estatales «el ritual y la creencia definen las reglas, prácticas y racional de mucha de la producción, distribución y consumo en la vida de un individuo». Se refiere a este modo de producción como un «modo de producción ritual», en el que «la actividad ceremonial crea una gran demanda (e insatisfacción) de actividades económicas dada 


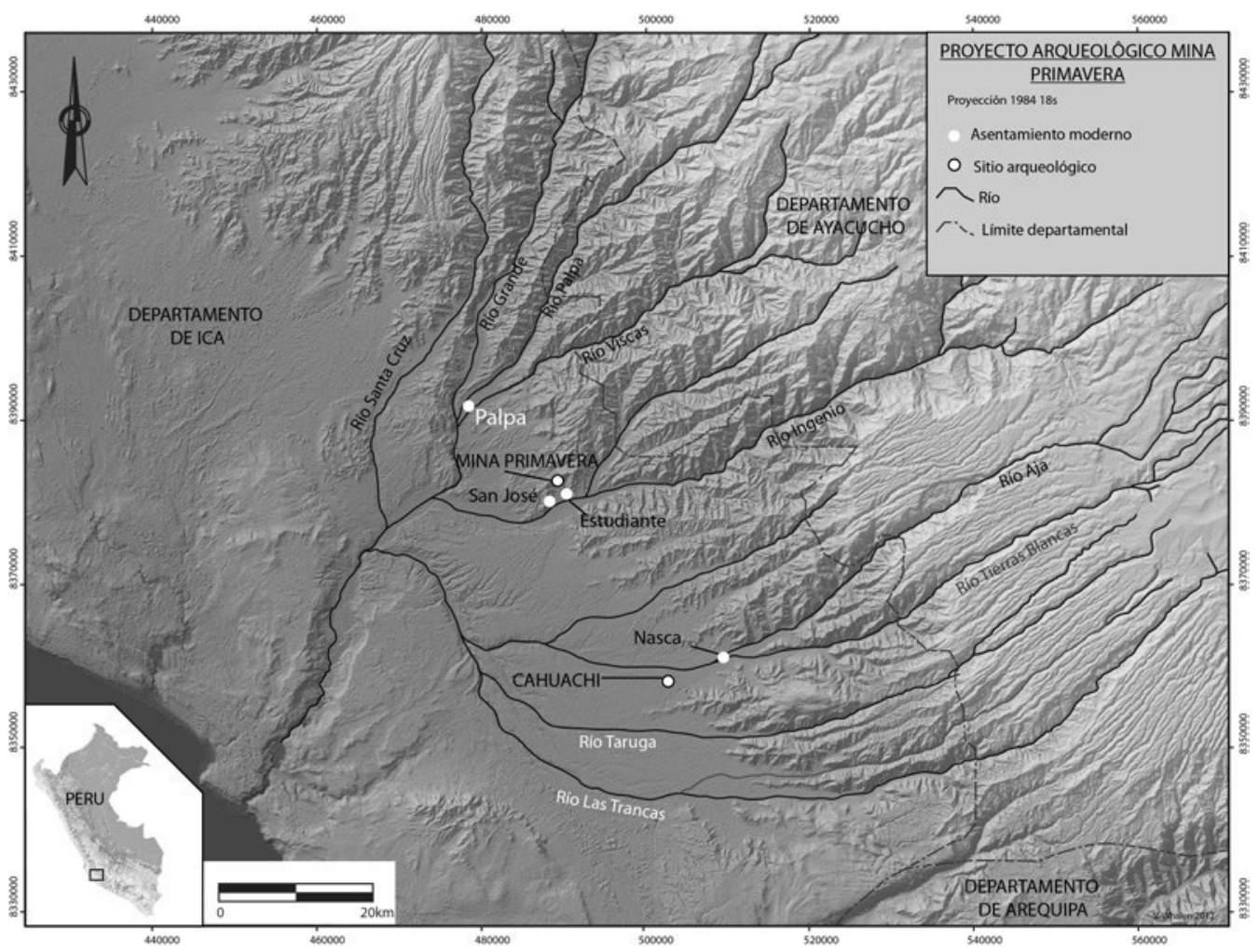

Figura 1. Ubicación de Mina Primavera en el área de Nasca y con respeto al sitio de Cahuachi (mapa de Verity Whalen y Hendrik Van Gijseghem).

la demanda». Similarmente, Elizabeth Bloxam (2011:153) sugiere que «períodos claves de cambios históricos, políticos e ideológicos, pueden provocar producciones intensivas de recursos específicos, dada su asociación con cultos religiosos emergentes». Estas nuevas imperativas económicas incluyen la producción y distribución de prácticas, mas también la extracción de materias primas del paisaje, incluyendo, en el caso presente, los minerales utilizados para producir innovadores pigmentos.

En este artículo presentaremos los resultados de las excavaciones realizadas en un contexto extremadamente particular: una mina de hematita intacta, ubicada en el valle del Ingenio (región Nazca; Fig. 1). Este contexto es un testigo de la estructura de la actividad primaria de producción de cerámica nasca: la extracción de materias primas. Brevemente describiremos la mina (véase también Vaughn et al. 2007, 2013a, 2013b) y reconstruiremos su cronología, incluyendo en ella la presencia humana, aunque esporádica, después del término de la explotación de la mina. Finalmente exploraremos las posibles implicaciones que estos hallazgos puedan tener en nuestro entendimiento de la ontología, que anima la compleja relación que los pueblos andinos tenían con el medio ambiente, las materias primas y los objetos materiales.

\section{La obtención y usos de la hematita en Nasca}

La hematita $\left(\mathrm{Fe}_{2} \mathrm{O}_{3}\right)$, algunas veces llamada oligisto u ocre, ha sido hallada en pequeñas cantidades en Cahuachi (Kroeber y Collier 1998; Petersen 2010:9), hipotéticamente un sitio de producción de cerámica policroma (Vaughn et al. 2006). Entre otros, ha sido encontrada en cachés rituales, 
frotada sobre cabezas trofeo, y depositada dentro de recipientes polícromos (Bachir Bacha y Llanos 2006: 66-68). En diversos contextos andinos, la hematita también fue usada como pigmento de textiles, objetos de madera, cosméticos, y murales (Yacovleff y Muelle 1934; Bonavia 1959, 1985; Phipps 1989), como pigmento corporal (Silva y Bahamondes 1969; Llagostera et al. 2000; Scalise y Di Prado 2006), y en ofrendas al mar (Murúa 1925). Dichos usos indican que más allá de sus cualidades estéticas, el material mismo se veía dotado de importantes asociaciones simbólicas. Se trata de uno de los recursos naturales que fue abonadamente explotado en varias áreas y épocas de la prehistoria andina (Prieto et al., 2016; Salazar et al. 2011).

La hematita, en conjunción con otros pigmentos, ha sido usada en espacios arquitectónicos en otras partes de los Andes (Wright 2010). Si las paredes de las plataformas del centro ritual de Cahuachi fueron pintadas, como es con frecuencia el caso en los Andes, grandes cantidades de hematita hubieran sido requeridas para las varias etapas de construcción (Nasca Temprano). De hecho, sabemos que por lo menos algunas de las paredes del complejo de Cahuachi fueron pintadas (Orefici y Drusini 2003: 78; Ríos 2007). Dichas actividades rituales, en adición a la producción de cerámica, estuvieron entre los probables contribuyentes a la tremenda demanda de materias primas, entre ellas la hematita. Finalmente, Eerkens ha demostrado que la cerámica del período Nasca Temprano incorporó la hematita en la elaboración de ciertos colores, notablemente el rojo y negro (Gorman et al. 2013; Vaughn et al. 2013a; Eerkens et al. 2014).

Información sobre minería en los Andes sugiere que fue un acto simbólicamente cargado. La minería histórica se ve generalmente acompañada de varios rituales (Nash 1972; BouysseGose 1986; Harris 2000; Cassagne 2005; Vaughn y Tricpevich 2013). Cobo, por ejemplo, ha propuesto que en el contexto andino, la mina era una especie de huaca (Cobo 1890-95, lb. 13, c. 11). La importancia de las minas en tiempos antiguos se ve apoyada por descubrimientos bastante excepcionales, como por ejemplo el de las ofrendas de Spondylus en una mina norteña (Shimada 1994). Dado lo que se sabe de las complejas relaciones que los antiguos pueblos andinos tenían con las fuerzas y seres telúricos, no debería sorprendernos que Gose describa la minería como «la violación culminante de la manifestación más central del apu: la misma montańa. Representa un salto cuántico más allá de cualquier otra actividad productiva en la intensidad de las relaciones entre la gente y los apus, y constituye una tensión definitiva para los dos» (Gose 1986: 303).

Proveniente de las mismas montańas, es posible que la hematita, como muchos otros metales, haya sido vista como la manifestación material de poderosas fuerzas terrestres. Así también lo atestigua su uso en contextos rituales. El papel de la hematita en la producción de cerámica podría también verse cargado con una importante dimensión simbólica o sobrenatural.

Habiendo establecido las posibles funciones y valores del mineral, podemos ahora preguntarnos que implica su extracción de la tierra. ¿Cuáles son las manifestaciones arqueológicas del «salto cuántico» del que habla Gose? Investigaremos estas preguntas en el contexto de nuestras excavaciones en mina Primavera.

\section{Mina Primavera}

Ubicada al norte del valle del Ingenio, en la formación portachuelo, de sedimentos marinos cretácicos intercalados con piroclásticos volcánicos (Montoya et al. 1994), mina Primavera (Fig. 2) fue originalmente registrada en el año 2004 (Vaughn et al. 2007). Es una pequeña caverna artificial, excavada en lo alto del acantilado, y a lo largo de una vena de hematita igualmente pequeña. Durante el siglo XX, mineros locales construyeron una pared dentro de la cavidad para convertirla en un almacén de herramientas y explosivos.

Mide aproximadamente unos 20 por 30 metros (Fig. 2), y su altura varía de 2 metros a 40 centímetros. Ya en la mina, se ven sobre la veta de hematita, que es de un rojo profundo, marcas antiguas de martillo. El piso de la mina, cubierto por fragmentos de herramientas y residuos mineros 
(Fig. 3), desciende en altura varios metros hacia el Sur y al Oeste, para formar tres galerías distintas, dos de las cuales (marcadas como galerías 1 y 2) poseen morteros de piedra directamente en el suelo de roca madre. La Galería 1 es la más accesible y a su vez, el espacio de entrada a la mina. La Galería 2 es accesible sólo al cruzar un paso angosto y de techo bajo al fondo de la Galería 1, donde el lecho rocoso se ha vuelto liso y pulido con lo que se presume ha sido el tránsito de tiempos antiguos. La Galería 3 desciende notablemente en altura hacia el Oeste de la entrada de la mina para formar un espacio independiente.

Un total de 60 metros cuadrados excavados dentro de la mina, durante cuatro temporadas (Vaughn et al. 2007, 2013a, 2013b) han revelado artefactos relacionados a la minería, al procesamiento de hematita, al consumo de alimentos y bebidas, y a lo que interpretamos como actividades rituales incluyendo el pago de ofrendas y la producción de música. El conjunto de cerámica recogida se ve dominado por piezas del Horizonte Temprano (Nasca Inicial) e Intermedio Temprano (cerámicas del Nasca Temprano, sobre todo de las fases 2 y 3), con algunos fragmentos cerámicos del Horizonte Medio (Fig. 4), incluyendo fragmentos de un vaso de tipo «lira» Chakipampa y de cantaros con representación de figuras humanas. Se conjetura que mucha de la presencia de material cerámico en la mina podría deberse al pago de ofrendas o a prácticas ceremoniales más que a motivos estrictamente pragmáticos. Aunque la muestra es comparativamente pequeña, la mina Primavera nos ha aportado proporciones de cerámica fina policroma superiores a las de los pueblos de Marcaya (Vaughn 2009) y Cahuachi (Silverman 1993), como se puede ver en la Tabla 1.

La estratigrafía de la mina está compuesta de una fina capa de arena desplazada por el viento y agua sobre estratos de escombros mineros de varios espesores, producto de la explotación de la mina en tiempos antiguos. En algunas de las unidades excavadas cerca de la entrada de la mina, un estrato delgado de arena traída por el viento indica que la explotación podría haber cesado por un tiempo antes de volver a continuar. Esta hipótesis se ve apoyada por la distribución vertical de cerámica, dado que fragmentos de los períodos Nasca 1 y 2 se encuentran en mayores cantidades en los estratos más bajos, y que fragmentos del período Nasca 2 se encuentran en los más altos. Así, podría suponerse un cambio en la frecuencia e intensidad de explotación desde las épocas más tempranas a las épocas finales del uso de la mina. Regresaremos a esta hipótesis más adelante en este mismo artículo.

Otros artefactos (Fig. 5) y descubrimientos incluyen los siguientes:

Herramientas de minería. Una gran cantidad de herramientas y fragmentos de piedra abundan en el piso de la mina, y de hecho componen las matrices de base y excavación. Hechas en arenisca local, estas herramientas incluyen palas, cinceles, martillos, picos, hachas de piedra, y piedras pulidoras, usadas todas en la extracción y el procesamiento de la hematita. En algunas áreas de la mina, casi toda la matriz excavada consiste en deshechos de herramientas de piedra. Por ejemplo, los dos estratos más bajos de una unidad de 2 por 2 metros (de más de 50 centímetros de profundidad) aportaron 259 hachas pesando más de 60 kilos. También se recuperaron un número de herramientas de madera utilizadas como pires, empuñaduras, y posiblemente antorchas (Fig. 6).

Tabla 1. Comparación de la frecuencia de fragmentos de cerámica polícroma en un sitio residencial (Marcaya), un sitio ceremonial (Cahuachi), y Mina Primavera

\begin{tabular}{|l|c|c|c|}
\hline & $\begin{array}{c}\text { Marcaya (Vaughn } \\
\text { 2005) }\end{array}$ & $\begin{array}{c}\text { Cahuachi } \\
\text { (Silverman 1993) }\end{array}$ & Mina Primavera \\
\hline número de fragmentos polícromos & 1269 & 999 & 242 \\
\hline proporción de cerámica polícroma & $12 \%$ & $22 \%$ & $30 \%$ \\
\hline proporción de bordes polícromos & $56 \%$ & $71 \%$ & $81 \%$ \\
\hline
\end{tabular}



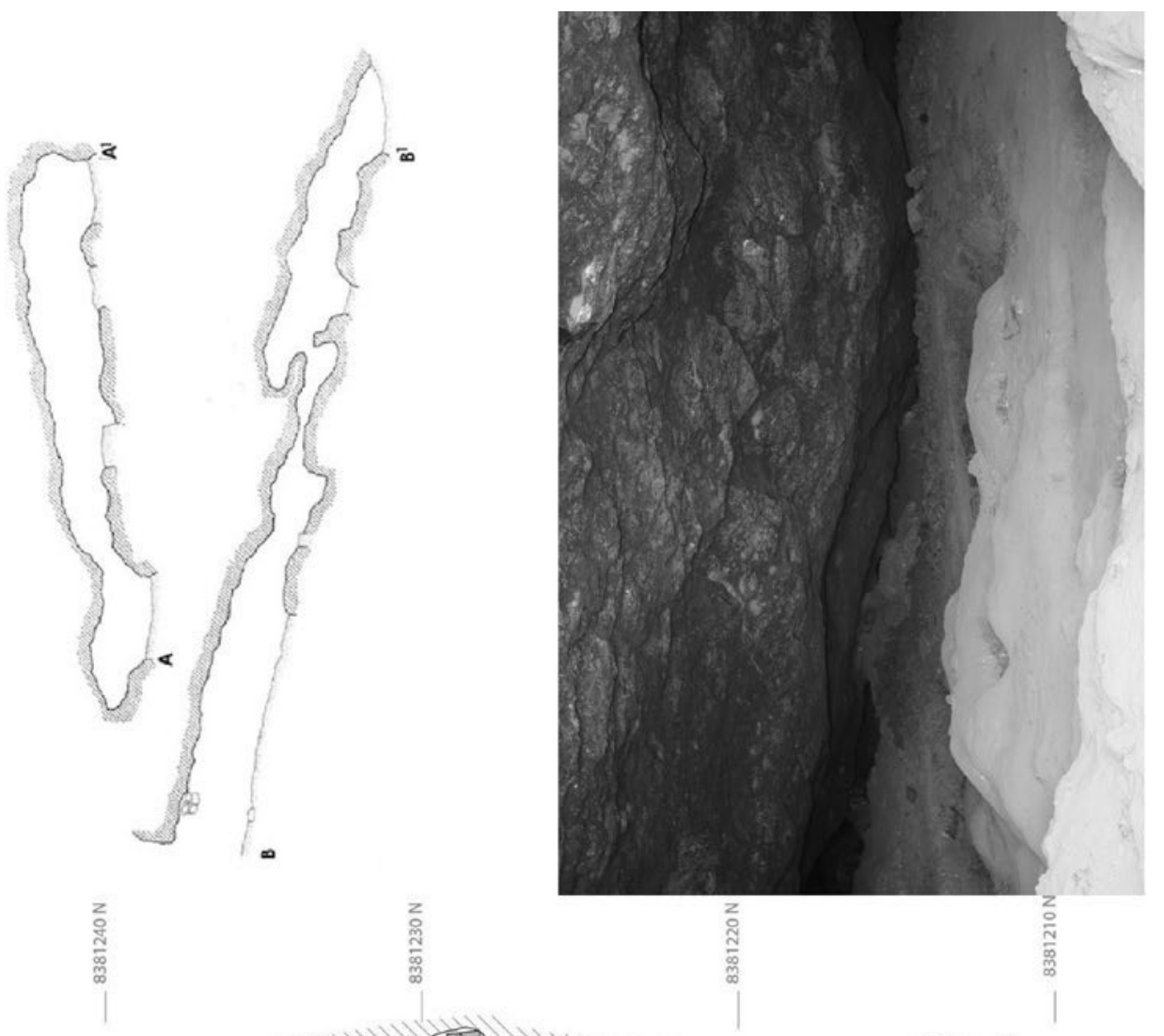

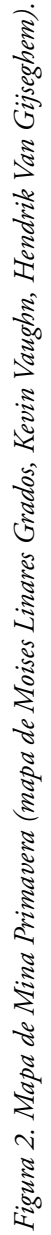

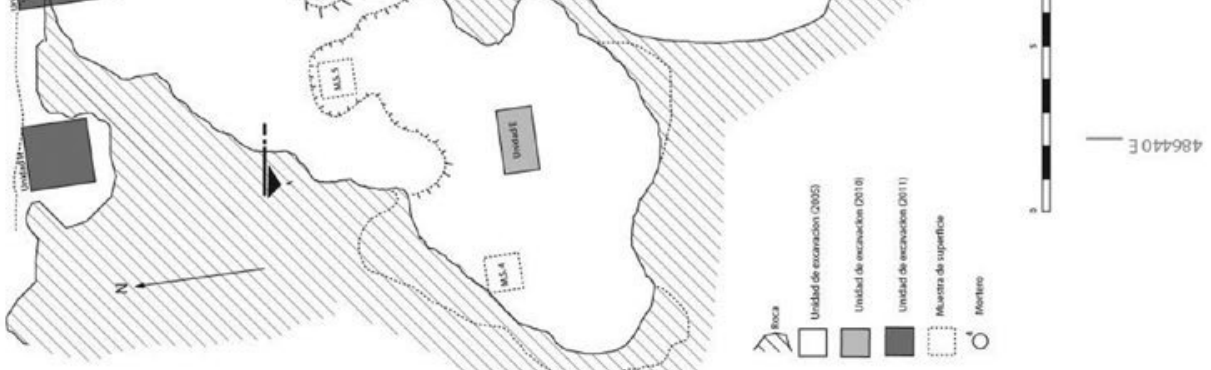




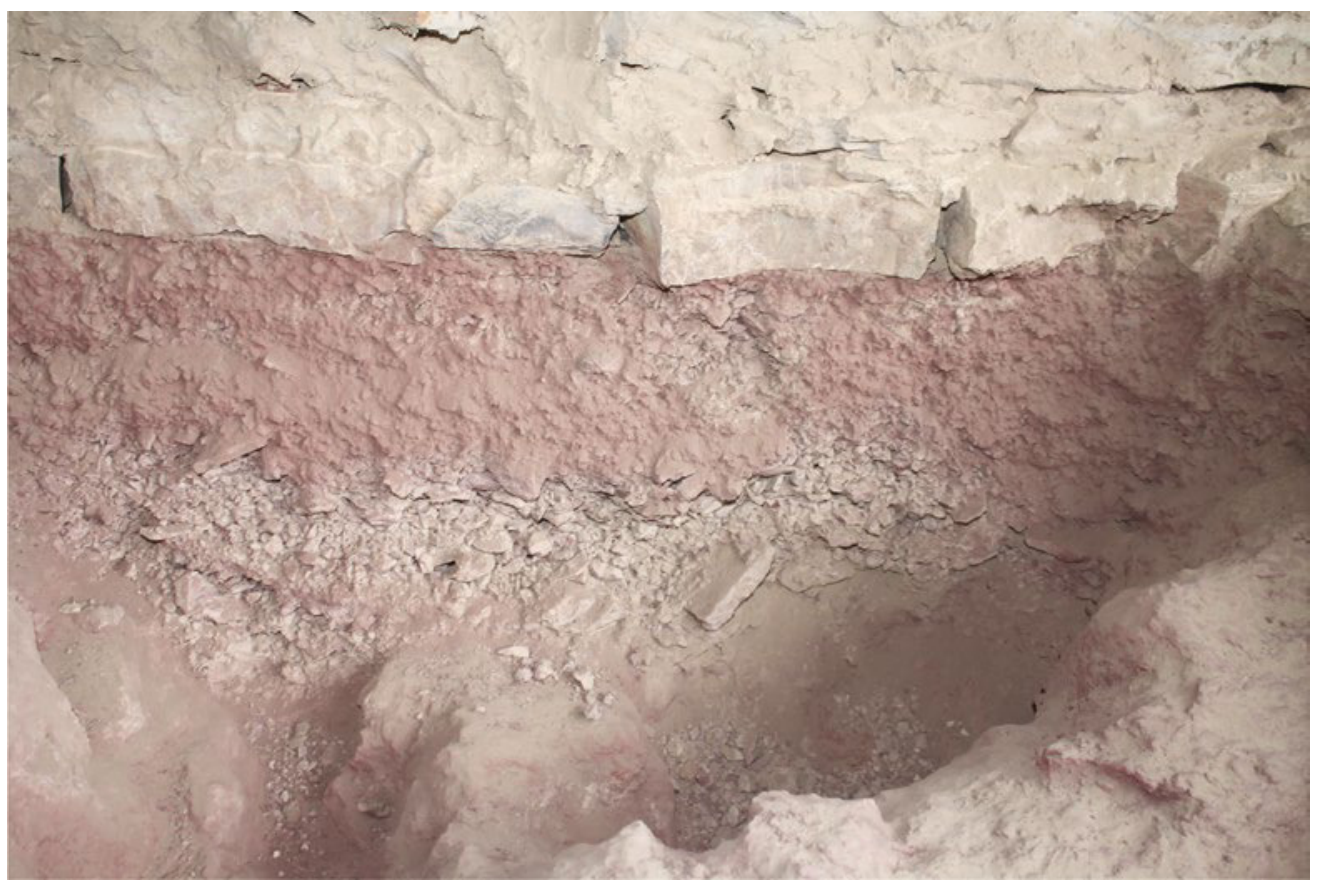

Figura 3. Ejemplo de estratigrafía. El estrato inferior arenoso corresponde a la explotación inicial del fin del Horizonte Temprano / inicio del Periodo Intermedio Temprano. El estrato superior contiene más evidencias de explotación intensiva correspondiente a Nasca Temprano del PIT (fotografia de Hendrik Van Gijseghem).

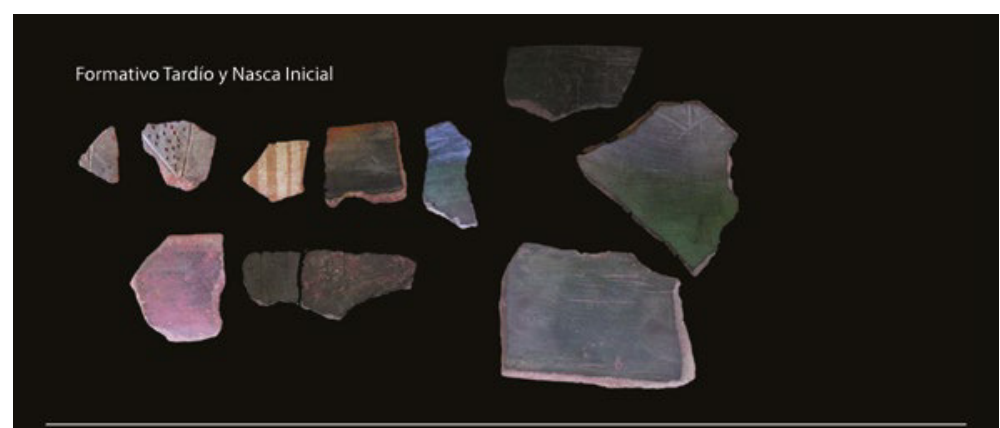

Figura 4. Muestra de la cerámica recogida de las excavaciones (fotografías de Kevin Vaughn)

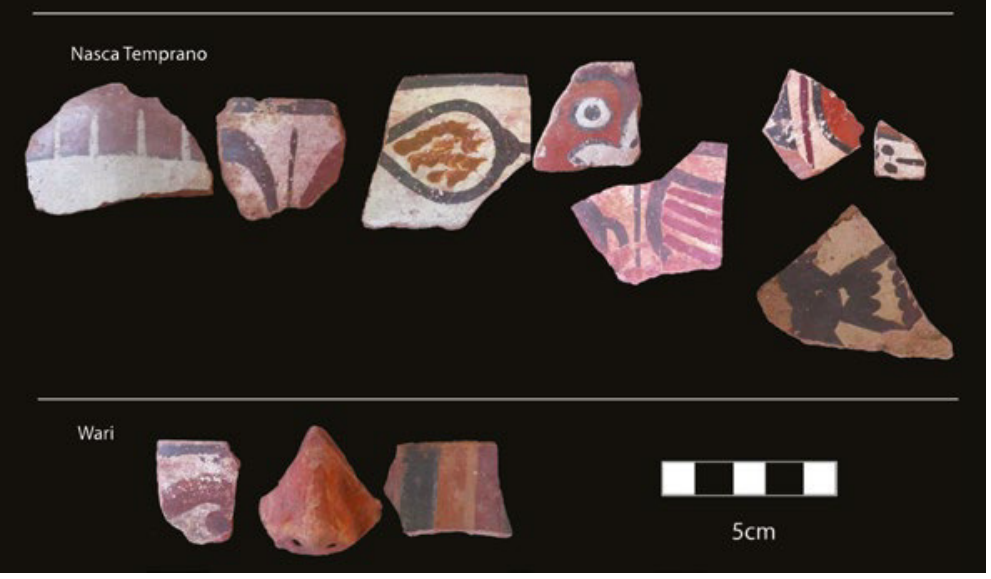




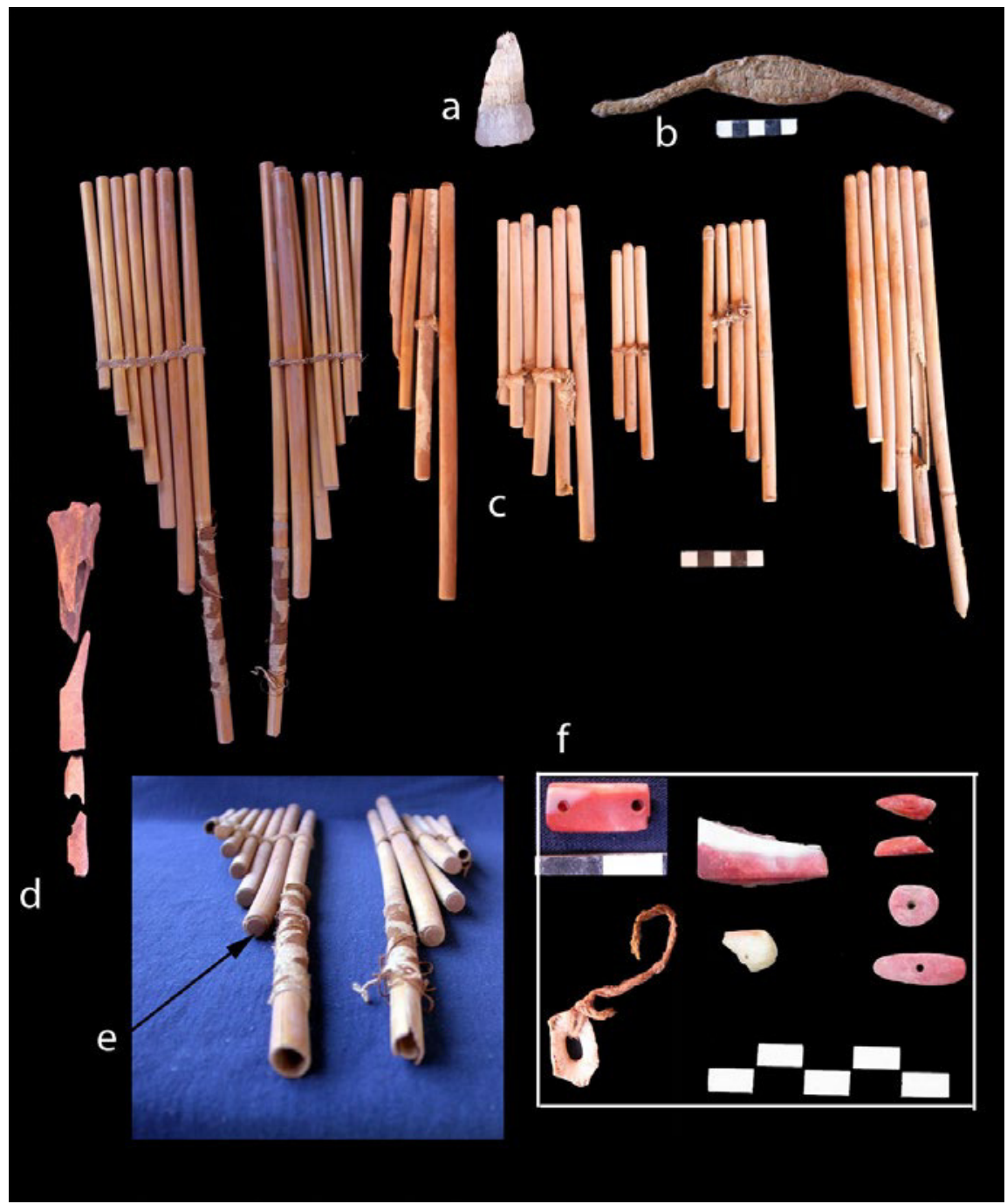

Figura 5. Hallazgos provenientes de las excavaciones de Mina Primavera. a. Bloque de sal; b. honda; $c$. Antaras; $d$. Fragmentos de flautas de hueso; e. Detalle de tapa de mate; f. cuentas y fragmentos de Spondylus (fotografias de Kevin Vaughn y Hendrik Van Gijseghem).

El conjunto de herramientas de minería tiene un notable parecido al que fue encontrado con el conocido «Hombre de Cobre» de la mina de Chuquicamata en Chile (Bird 1979; Craddock et al. 2003), lo cual sugiere que en la antigüedad podría haber existido una caja de herramientas básica y común.

Textiles. Una gran cantidad de tela fue recuperada de casi todos los contextos, siendo la vasta mayoría tejidos simples de algodón, teñidos por la exposición a la hematita. El análisis de Sara Kerchusky (sf.) ha revelado una gran variedad de fajas y tramas, lo cual sugiere que el conjunto proviene de una diversidad de tradiciones textiles y de varias comunidades tejedoras. El uso es extensamente visible en las piezas del conjunto textil, muchos de cuyos artículos muestran desgarres, algunos de los cuales fueron cosidos. Es probable que los textiles hayan tenido varios usos, entre los cuales estarían la recolección y el transporte de minerales, la vestimenta y hasta vendas para proteger las manos de los mineros usando martillos. 


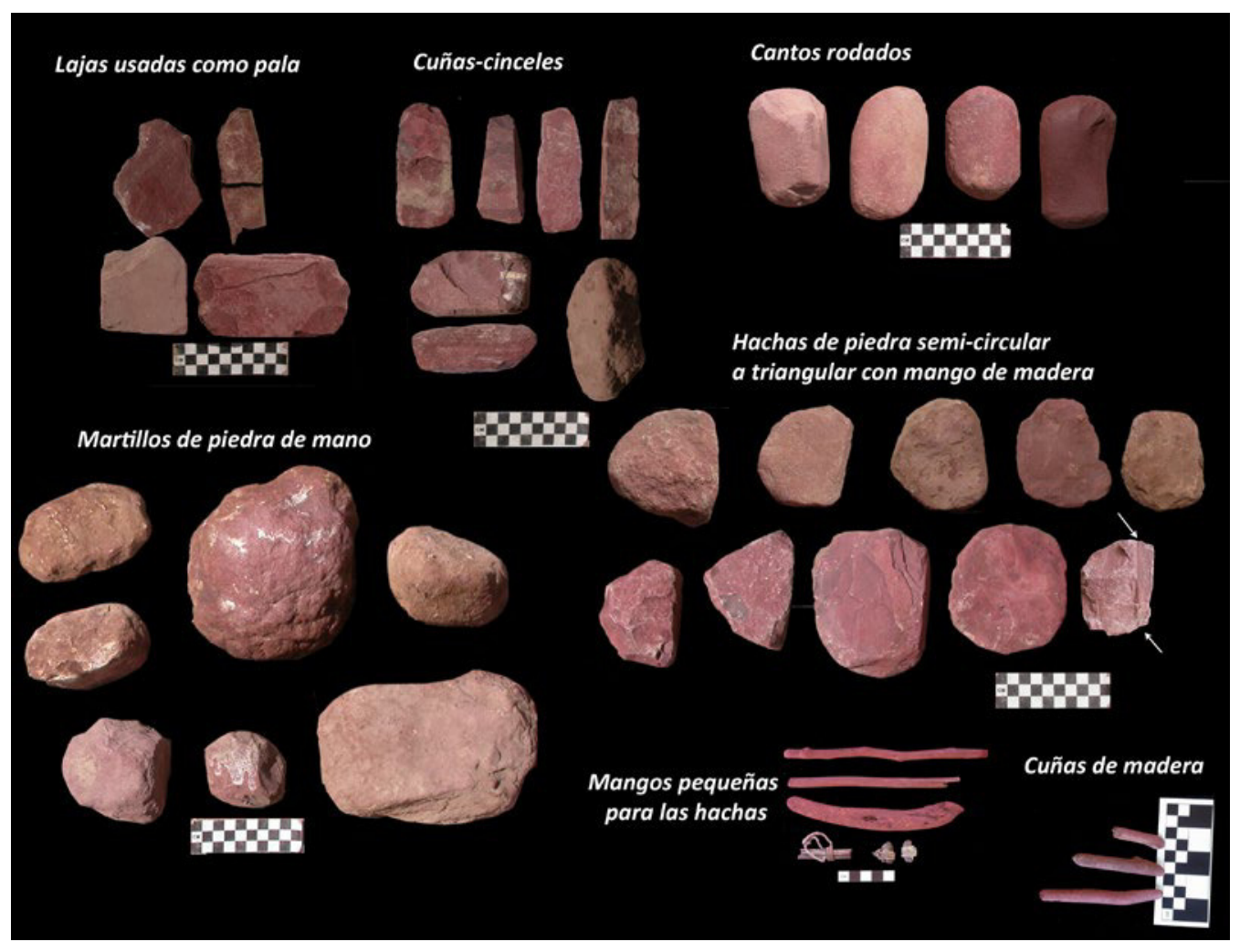

Figura 6. Ejemplos de herramientas de piedras hallados en Mina Primavera (fotografias de Kevin Vaughn).

Un pequeño número de textiles teñidos y pedazos de cuerda también fueron hallados, incluyendo una pequeña borla multicolor de tela nasca fina. Piezas de lana también fueron halladas en pequeńas cantidades.

Desechos orgánicos y de sustento. Las condiciones áridas y estables dentro de la mina, Primavera han protegido un gran número de bienes perecederos, entre los cuales se encuentran en abundancia grandes fragmentos de calabaza y restos de maíz. Se conjetura que el maíz fue consumido dentro de la mina por los obreros, lo cual sugiere que los períodos de trabajo eran lo suficientemente largos para requerir el consumo de alimentos en el mismo sitio. Similarmente, las calabazas, bastante fragmentadas, podrían haber sido usadas para almacenar y beber agua. Debido a que la mayoría de los fragmentos están notablemente teñidos, se especula que las calabazas podrían también haber sido usadas en la colección y el transporte de la hematita (aunque aquello pueda haber sido también el resultado de un proceso posterior al abandono de dichos materiales). El corpus botánico también comprende restos de pacae, lúcuma, maní, achupalla, y una pequeńa cantidad de hojas de coca.

Rasgos de piedra pulida. Treinta y tres morteros han sido registrados entre las áreas de la mina donde el suelo de roca es visible. La mayoría de ellos fueron encontrados ya expuestos en la superficie del sitio, mientras que muchos otros, habiendo sido enterrados por escombros mineros, fueron encontrados por medio de excavaciones. Es así que se supone que el número total de estos instrumentos debe exceder el número registrado hasta el momento. Todos los morteros fueron encontrados en las Galerías 1 y 2, lo mismo que en la entrada a la Galería 1. No se han documentado morteros en la Galería 3, a pesar de haberse realizado excavaciones en ambos lugares. Hemos registrado estos instrumentos como morteros usados en el procesamiento de la hematita, aunque inspecciones más detalladas han demostrado que había cierta variabilidad en su uso. Basándonos 

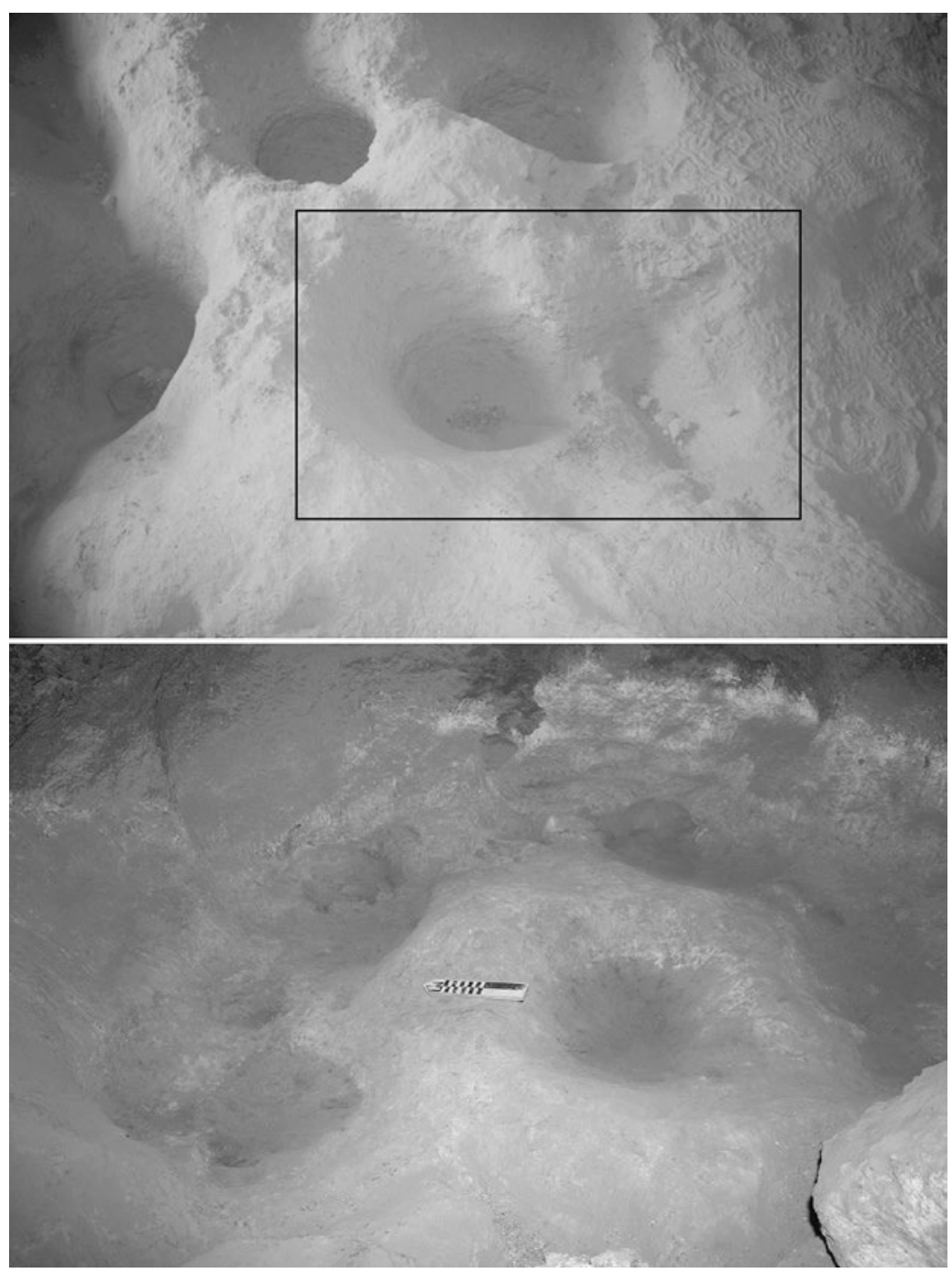

Figura 7. Dos tipos de morteros encontrados en Mina Primavera (fotografias de Verity Whalen).

en su tamaño y distribución, los hemos clasificado como morteros pequeños y grandes. Parecen variar por su cantidad de desgaste y por su incidencia, a veces solos o en pares (Fig. 7). Cinco morteros grandes en la Galería 1 poseen a su vez morteros satélites-o pequeños morteros unidos a los morteros principales por medio de una superficie redondeada, y pulida sugiriendo el uso simultáneo de ambos.

Los morteros grandes y pequeños se diferencian también en cuanto al uso aparente en sus superficies. La mayoría de los morteros grandes exhiben un desgaste mínimo a moderado con superficie más tosca, mientras que los morteros pequeños muestran rastros de uso extensivo y superficie más pulida. Interpretamos estas diferencias como índices de dos posibles etapas en el procesamiento del mineral. En este caso, proponemos que, en la primera etapa, la hematita fue fragmentada en trozos más pequeños haciendo uso de los morteros grandes, y que en la segunda etapa, los trozos de hematita fueron molidos en los morteros pequeños hasta hacerse un polvo fino.

En la Galería 1, el proceso de pulverización ocurría generalmente en un mortero grande unido a un mortero pequeño, formando así lo que referimos como una «estación mortera». En la Galería 2, 
por otro lado, el procesamiento secundario ocurría casi siempre en los morteros pequeños que se encuentran separados, aparte de los morteros hechos de las mismas formaciones rocosas de la mina, y ubicados por separado, en partes elevadas de la base.

Estas diferencias son significativas. Las estaciones morteras de la Galería 1 permiten a una sola persona trabajar continuamente en el procesamiento de la hematita, elaborándola desde grandes fragmentos hasta hacerse de ella un polvo fino, primero dividiendo los fragmentos en el mortero grande, y luego transfiriendo el material al mortero adjunto para molerlo. El diseño de estas estaciones permitía mover la hematita directamente de los morteros grandes a los pequeños para mayor procesamiento; el uso de las superficies de ambos atestigua a la repetición de tal acto. Las marcas son notablemente diferentes en la Galería 2, dónde las estaciones morteras secundarias no están presentes. En su lugar, los morteros de la Galería 2 comprenden lo que se denominó como un «complejo mortero», el cual consiste en múltiples morteros grandes separados por morteros pequeños. En lugar de centros de procesamiento personales, la escala del complejo en la Galería 2 sugiere una cooperación simultánea entre varias personas — algunas quebrando los fragmentos de hematita cruda en los morteros grandes, mientras que otras continúan el refinamiento de la hematita en los morteros más pequeños hasta convertirla en polvo-.

Como veremos más adelante, este segundo arreglo nos permitirá desarrollar diferentes hipótesis sobre cambios en la estructuración del trabajo en mina Primavera.

Otros hallazgos. Algunas de nuestras evidencias sugieren que las actividades dentro de la mina fueron más diversas que la extracción y el procesamiento de pigmentos. Entre estos hallazgos, hay una variedad de objetos, o fragmentos de objetos que son tradicionalmente asociados con bienes suntuarios o practicas rituales. Por ejemplo, algunas cuentas de Spondylus princeps y sus fragmentos han sido encontrados en contextos diversos. En los Andes, este molusco es generalmente utilizado en rituales y se ve frecuentemente asociado con el agua y la fertilidad (Pillsbury 1996). Cuentas hechas de madera y hueso también podrían haber sido parte de otros artículos de adornos personales.

Otros hallazgos incluyen una honda muy bien preservada y hecha de tela, la cual fue encontrada cerca de la superficie. Esta no es una conjetura diagnóstica, más su presencia en Capa A sugiere que podría haber sido depositada en la mina después de que las actividades de extracción hubieran culminado.

Finalmente, hemos recuperado evidencia de actividades musicales, las cuales también ocurrieron después del procesamiento de la hematita (véase la discusión de los fechados radiocarbónicos). Entre la evidencia recuperada se encuentran fragmentos de una o más flautas de hueso, además de un par de antaras, las cuales fueron ubicadas al fondo de la Galería 1. Cada antara es una réplica idéntica de la otra, con siete varas de caña atadas con una cinta de algodón según el orden disminuyente de sus tamańos. La vara más larga de cada par se ve atada con una cinta de algodón marrón en la cual se puede ver un diseño sobre el que no tenemos conjeturas por el momento. Las cinco varas centrales de cada par tienen discos hechos de calabaza tapando cada base. De hecho, debido a que estas antaras, que son frágiles, fueron encontradas en buen estado de preservación (sin deterioro ni fracturas), se cree que fueron depositadas cuidadosamente y que subsecuentemente han sido encontradas en su contexto primario (el único hallazgo de tal tipo hasta el momento). La presencia de estas antaras parece no constituir una anomalía, ya que un total de 15 tapones de calabaza como los previamente mencionados fueron encontrados en el sitio, sugiriendo así que, otras antaras fueron tocadas en la mina en otros momentos. Más aún, la casi totalidad de estos tapones fueron encontrados en unidades de excavación ubicadas cerca de la entrada de la mina, lo cual indica que se tocaba música en múltiples ocasiones, y que, en algunas de ellas los tapones mencionados se desprendieron de sus cañas. Finalmente, sabemos de una ocasión en la cual los instrumentos musicales fueron depositados ceremonialmente en el interior de la Galería 1 . Nuestros datos indican que dichas actividades rituales ocurrieron después de que la mina haya sido abandonada, sugiriendo que esta singular, llamativamente roja rajadura al lado de un acantilado podría haberse convertido (o continúe siendo) una huaca. 
Tabla 2. Fechados AMS proveniente de Mina Primavera, presentados en orden de edad, con los más antiguos arriba y los más recientes abajo, y calibrados según la curva INTCAL 09

\begin{tabular}{|c|c|c|c|c|c|c|}
\hline \# de Muestra & Galería & Unidad & Capa & Fecha C14 & Años calibrado $2 \sigma$ & Nota \\
\hline AA100191 & 1 & $\mathrm{~K}$ & $\mathrm{C}$ & $2077 \pm 40$ & 199 a.c. - 4 d.C. & \\
\hline AA100187 & 3 & $\mathrm{E}$ & $\mathrm{B}$ & $1978 \pm 40$ & 54 a.C. - 92 d.C. (95.4\%) & \\
\hline AA100190 & 1 & $\mathrm{~K}$ & B & $1971 \pm 40$ & 49 a.C. - 93 d.C. $(94.3 \%)$ & \\
\hline AA72021 & 1 & $\mathrm{~T} 1$ & $\mathrm{~B}$ & $1961 \pm 43$ & 48 a.C. -128 d.C. & \\
\hline AA72024 & 1 & 3 & $\mathrm{~A} 2$ & $1951 \pm 35$ & 3 a.C.-126 d.C. $(92.5 \%)$ & \\
\hline AA100192 & 1 & $\mathrm{~L}$ & $\mathrm{C}$ & $1922 \pm 40$ & 1 a.C. - 179 d.C. $(95.7 \%)$ & \\
\hline AA72023 & 1 & 2 & $\mathrm{~B}$ & $1901 \pm 44$ & 17-230 d.C. & \\
\hline AA100193 & 1 & $\mathrm{~L}$ & $\mathrm{~B}$ & $1888 \pm 40$ & 50-231 d.C. (98.1\%) & \\
\hline AA100186 & 3 & $\mathrm{E}$ & $\mathrm{C}$ & $1864 \pm 40$ & 65-240 d.C. & \\
\hline AA94038 & 3 & $E$ & $\mathrm{D}$ & $1832 \pm 35$ & 83-254 d.C. (99.6\%) & \\
\hline AA100185 & 2 & $\mathrm{C}$ & B1 & $1771 \pm 40$ & 134-353 d.C. $(97.6 \%)$ & \\
\hline AA94039 & 2 & $\mathrm{C}$ & $\mathrm{B}$ & $1722 \pm 35$ & 241-403 d.C. & \\
\hline AA94681 & 1 & $\mathrm{~F}$ & B & $1480 \pm 55$ & $\begin{array}{l}526-655 \text { d.C. }(83.1 \%) ; 434-493 \\
\text { d.C. }(14.2 \%) ; 506-521 \text { d.C. }(2.7 \%)\end{array}$ & ántara \\
\hline AA100188 & 1 & $\mathrm{~F}$ & F3 & $1348 \pm 56$ & 580-779 d.C. (99.3\%) & ántara \\
\hline Beta 195717 & 1 & 1 & A & $990 \pm 70$ & 940-1210 d.C. (95.7\%) & \\
\hline AA72022 & 1 & 2 & A & $505 \pm 43$ & $\begin{array}{l}\text { 1316-1355 d.C (15.1\%) 1388-1455 } \\
\text { d.C. }(84.9 \%)\end{array}$ & \\
\hline AA100189 & terraza & $\mathrm{H}$ & A & $380 \pm 38$ & $\begin{array}{l}\text { 1442-1529 d.C (59.4\%); } 1544-1548 \\
\text { d.C. }(0,7 \%) ; 1550-1634(39.8 \%)\end{array}$ & \\
\hline
\end{tabular}

\section{Cronología: Las fechas radiocarbónicas}

Diecisiete fechas AMS obtenidas de fragmentos de maíz y calabaza concuerdan con nuestra reconstrucción de la cronología basada en la distribución cerámica (Tabla 2). La mayoría de las estimaciones calibradas varían desde el segundo milenio a.C. hasta el tercer siglo d.C., es decir, dentro de lo que se conoce como el final del Horizonte Temprano y la primera parte del Período Intermedio Temprano. Como es de esperarse, las fechas más antiguas provienen de la Galería 1, y por lo general se encuentran en mayor concentración cerca de la entrada de la mina (donde, lógicamente, el proceso de extracción habría tenido inicio). Cuatro de las fechas más antiguas (AA100190, AA100191, AA100192 y AA100193) provienen con certeza de contextos Nasca 1 y fueron encontradas cerca de la entrada a la Galería 3. A estas se les interpreta como índices del momento inicial de la explotación de esa galería. Las tres fechas más recientes provienen de la Capa A, del estrato generado después del abandono de la mina. Las edades agrupadas de estas fechas se reparten proporcionalmente entre 71-130 cal. d.C.

Dos fechas AMS adicionales fueron obtenidas de algunos fragmentos de antaras: la primera, de un pequeño disco de calabaza recuperado cerca a los instrumentos musicales (AA94681); la segunda, de un trozo de hilo de algodón proveniente de las mismas antaras (AA100188). Ambas fechas (agrupadas desde 565 a 669 d.C.), son comparativamente tardías y apoyan las posibilidades 
de que se haya tocado música en la mina y que las antaras encontradas hayan sido depositadas como ofrendas después de que las actividades mineras habían cesado, como lo indican los fechados de radiocarbono sobre residuos alimenticios y la cerámica. Nuestras fechas AMS adicionales también soportan la hipótesis de que el lugar se haya mantenido presente en la memoria social de la gente de Nasca, y que haya sido venerado, quizás como un espacio liminal entre el mundo de los seres vivientes y el de los ancestros, como muchas cavernas lo fueron en la antigüedad del nuevo mundo (Whitehouse 1992: 9; Brady y Rissolo 2006).

Debería también recalcarse que las fechas de las antaras las sitúan cronológicamente al principio de Horizonte Medio según los registros pertinentes a la región Central de Nazca en el área de Palpa (Unkel et al. 2007, 2012; Reindel 2009). Dada, especialmente, la falta de material cerámico Nasca Tardío, las antaras podrían ser asociadas con los pocos fragmentos de material cerámico Wari encontrados en mina Primavera. El consenso general de que la mayoría de las antaras del período Nasca Temprano fueron hechas de cerámica en lugar de cańa (Haeberli 1979; Dawson 1964; Gruszczynska-Ziolkowska y Prusik 2000) apoya esta hipótesis. Esta observación tiene implicancias importantes en nuestra reconstrucción del paisaje sagrado y de las estrategias de consolidación política Wari en Nazca, las cuales exploraremos en la última sección de este artículo.

El registro radiocarbónico proveniente de residuos de alimentos y recipientes de calabaza indica que la exploración de la mina Primavera ocurrió en un plazo de 300 a 400 ańos, lo cual coincide con el período de desarrollo y apogeo de Cahuachi como centro ceremonial. Después de excavaciones limitadas, Vaughn et al. (2007) estimaron inicialmente que la extracción de 3700 toneladas de hematita en un período de 1400 ańos, se hubiera realizado a un paso promedio de 2.65 toneladas por año. En vista de los hallazgos más recientes, y de la reducción del período estimado de explotación, la figura más probable se encuentra en los linderos de 10 toneladas al año (sobre un período estimado de 350 ańos), lo cual constituye un promedio de 1.88 metros cúbicos de material extraído, procesado, removido y transportado anualmente. En la siguiente sección evaluaremos si dicha explotación fue gradual y continua o si se sometió a cambios en su organización e intensidad.

\section{Reconstrucción de cuatro momentos decisivos en la historia de mina Primavera}

La evidencia hasta ahora reunida de la mina Primavera nos permite trazar su historia a grandes rasgos y establecer cuatro momentos principales, los cuales se ven respaldados por el registro de radiocarbono, el corpus cerámico, la estructura del espacio, las características de los morteros y los perfiles estratigráficos.

El primer intervalo documentado corresponde al uso de la mina durante el final del Horizonte Temprano y Nasca 1 . Aunque material del período Nasca 1 se encuentra a través de toda la mina, dicho material se encuentra mezclado con material de otras épocas, sugiriendo que no es de contexto primario. Los contextos más confiables provienen de la entrada a la Galería 3, cerca al exterior de la mina, donde lógicamente la explotación más temprana hubiera tomado lugar. Resulta interesante que estos contextos carezcan por completo de morteros de piedra, llevándonos a creer que la materia prima fue procesada en algún otro lugar o de manera diferente. Una característica peculiar del contexto Nasca 1 es la ausencia de textiles. La Galería 3, inclinándose en bajada desde las unidades donde estratos del período Nasca 1 fueron identificados, también carece de morteros. Las excavaciones en dicha sección han sido limitadas, pero hasta ahora consistentes con la hipótesis de que esta es la galería más antigua, ya que se ve asociada con fragmentos de cerámica Nasca 1 y 2. Hasta cierto punto, el registro radiocarbónico también respalda esta hipótesis.

La primera instancia de explotación documentada, entonces, ocurrió entre el primer siglo a.C. y el primer siglo d.C. La explotación puede haber sido esporádica. No hay evidencia de uso de textiles o de morteros de piedra. El mineral puede haber sido extraído en su forma cruda y transportado 
a otro lugar para ser procesado en polvo. Cerámica negra fina del período Nasca 1 y otros cuencos (también bien hechos), fueron utilizados, rotos y descartados como parte del oficio, del consumo de alimentos, o como ofrendas rituales.

El contexto regional asociado con la explotación inicial incluye la fundación de Cahuachi como un centro regional importante de elaboración de engobes cerámicos de colores.

En un segundo momento la explotación de la mina se extendió en dirección este hacia la parte superior de la Galería 1. Registros de radiocarbono y material cerámico sugieren un período de uso durante Nasca Temprano. Residuos de cerámica fina, entre otros, podrían indicar que la minería fue acompañada de un componente ritual. En aquel momento, los mineros usaban morteros para triturar la hematita hasta obtener el polvo que era extraído de las minas. El tipo de mortero más común es la "estación mortera», donde un solo individuo inicialmente trituraba el material hasta obtener trozos gruesos antes de transferirlos a los «morteros satélites» para terminar su procesamiento, previo al transporte. La organización de dicha labor comprendía el uso de textiles como bolsas o forma de amortiguamiento.

Esta época vio un aumento en la importancia regional de Cahuachi, y las actividades de dicho centro podrían haber alimentado la demanda de hematita utilizada en la elaboración de cerámica, ofrendas rituales, y actos ceremoniales.

El tercer momento representa probablemente el apogeo de Cahuachi y la mina Primavera, y se ve asociado con cerámica del período Nasca 3. En este período, la extracción de hematita se adentró en las profundidades de la montaña, llegando hasta lo que hoy conocemos como la Galería 2, lugar donde escasean la luz y el oxígeno. Aun así, complejos morteros de talla considerable fueron modelados del lecho rocoso. La disposición espacial de los morteros utilizados en las dos etapas de procesamiento sugiere que diferentes obreros cumplían diferentes funciones, trabajando simultáneamente en ambos tipos de mortero. Dicha disposición espacial no impide que un número moderado de trabajadores hayan refinado fragmentos de hematita, mientras que otros obreros presumiblemente se hayan ocupado de extraer el mineral. La materia prima entonces habría sido traída primero a los morteros grandes donde la primera etapa del procesamiento tomaría lugar, y finalmente trasladada a los morteros más pequeños.

En comparación con períodos previos, la imagen que se forma de la Galería 2 es de una labor más compleja y colectiva, de una división más rigurosa del oficio, lo cual probablemente significó una aceleración e intensificación de la explotación minera.

En un cuarto momento, aunque Cahuachi mantuvo su importancia ritual y simbólica, la construcción monumental cesó después del período que corresponde al material Nasca 3. Esto podría sugerir una disminución de prácticas ceremoniales, de importancia regional, o un cambio en las actividades ligadas al sitio. Sin embargo, Cahuachi nunca recuperó la prominencia de sus épocas de apogeo (Silverman 1993; Orefici 2011). Esto coincide con el aparente fin de la explotación de mina Primavera. Aun así, unas cuantas cerámicas y fechas radiocarbónicas sugieren que mina Primavera, continuó siendo visitada esporádicamente después de que las actividades de extracción fueron interrumpidas.

Hemos argumentado que en algunas de estas visitas se tocaba música con suficiente frecuencia como para haber dejado como rastro los discos de calabaza previamente mencionados, discos recuperados en nuestras excavaciones. Basándonos en la distribución de estos discos, conjeturamos que muchas de estas actividades parecen haber tomado lugar cerca de la entrada de la mina, quizás por sus propiedades acústicas distintivas. En por lo menos una ocasión, un miembro del grupo de visitantes cuidadosamente tendió sobre el piso un par de antaras idénticas y las enterró bajo los escombros mineros al fondo de la Galería 1. Las antaras fueron encontradas sin mayor alteración, lo cual indica que fueron depositadas después de los períodos de actividad principales de la mina. Fechas de radiocarbono indican que dichos actos rituales probablemente ocurrieron en el Horizonte Medio, una hipótesis consistente con la presencia, aunque en pequeñas cantidades, de 
fragmentos de recipientes Wari asociados con actividades ceremoniales de elite (Cook 1984-1985; Edwards 2010: 341; 2013).

Es posible que dichas visitas, ofrendas y ceremonias, representen una tentativa de apropiamiento del paisaje sagrado Nasca de parte de nuevos poderes Wari. De hecho, esta ha sido una táctica de conquista y consolidación bastante común en los Andes (v.g. Gose 1993; Greene 2002; Glowacki y Malpass 2003; Schreiber 2005; Williams y Nash 2006; Wernke 2012), según la cual, miembros de un grupo invasor se presentan en relación favorable con genealogías locales encarnadas en sitios importantes del paisaje. Probablemente sea significativo que la música sea un componente importante de la práctica ritual andina, usada para comunicarse con los ancestros (Olsen 2002).

Por lo tanto, es probable que la mina, en virtud de su apariencia o de la substancia que producía tradicionalmente, adquirió o mantuvo el estatus de huaca (o algo similar), y permaneció como una localidad simbólicamente importante, meritoria de ceremonias, ofrendas y ritual.

\section{Conclusión: hematitas, ritual y paisaje en la antigua Nazca}

Vaughn y Neff (2004; veáse también Vaughn y Van Gijseghem 2007) se han servido de caracterización química de pastas cerámicas para respaldar la hipótesis de que la cerámica polícroma del período Nasca Temprano fue producida en la vecindad de Cahuachi. A su vez, los pigmentos no refinados y las herramientas utilizadas en la elaboración de cerámica encontrada en Cahuachi apoyan la idea. Los tintes rojos y negros del período Nasca Temprano eran compuestos de óxidos de hierro correspondientes químicamente a la muestra de hematita que Kroeber recolectó de Cahuahi (ahora en el Field Museum de Chicago). De hecho, esta muestra es composicionalmente idéntica a otras provenientes de la misma mina Primavera (Eerkens et al. 2009). La suma de esta evidencia converge en su contextualización del vínculo entre la explotación de mina Primavera y el culto de Cahuachi. Por lo tanto, no es una coincidencia que se vea una congruencia entre el período de explotación de la mina y el período en el cual Cahuachi fue un centro ceremonial y de peregrinaje de igual importancia. Es posible que la demanda de hematita se haya debido a la decoración o pintura de las fachadas de las plataformas del centro ceremonial, y que su uso ritual se haya extendido a entierros y a las ofrendas de las conocidas cabezas trofeo. Aun así, su uso en la pigmentación de cerámica queda como otro foco importante de demanda.

Nosotros sugerimos además que la elaboración de cerámica pueda haber tenido una dimensión escénica. La mina Primavera era un lugar sagrado y poderoso, como a su vez lo era la substancia que producía. Más que una mercancía, era una substancia potente que mantenía un fuerte lazo con su lugar de origen. Es decir, la hematita era vista como una substancia de la tierra.

Si la hematita tenía un vínculo con lugares de poder y con sus seres, entonces el papel del ceramista era más que el de meramente producir un recipiente o pintar algún tema iconográfico. Él o ella era el adiestrado orquestador de las varias fuerzas activas y potentes encarnadas en la substancia con la que él o ella trabajaba, tejiendo así una compleja gramática compuesta de varios materiales, imágenes y fuerzas: la cerámica, el agua, el fuego, y las varias substancias minerales cuyos orígenes se veían representados en la mente del ceramista y, por extensión, la del destinario final de sus obras. Los recipientes polícromos distribuidos durante eventos ceremoniales en Cahuachi eran más o menos un microcosmos de la constelación de las fuerzas inmanentes en el paisaje, una vez que a dichas fuerzas se les hubiera dado una forma material portable. Dado el amplio uso de hematita en rituales y ceremonias y su aparente potencia y sacralidad, ¿qué nos llevaría a creer que dichas propiedades serían perdidas al transformarse en tinte? En lugar de ello, proponemos que cuando una persona de la antigua cultura Nasca miraba y tocaba una vasija de cerámica, ella veía un recipiente, que a su vez era también una iconografía, y que por último estaba dotado de varias fuerzas materiales, entrelazándose así estos diferentes aspectos en un solo objeto. 
Como un corolario, más allá de los aspectos instrumentales pertinentes a la adquisición de la hematita, emerge una preocupación con la mitigación ritual de su extracción. Lo que se ve en la mina Primavera es un sitio sagrado e importante que proveyó al antiguo pueblo nasca de substancias poderosas, sitio que aún después de haber terminado con sus funciones abastecedoras, se mantuvo simbólicamente potente, digno de ceremonias, quizás como una línea de comunicación sagrada con las fuerzas cósmicas o con los ancestros. Nuestra evidencia también sugiere que podría haber sido suficientemente importante en el paisaje sagrado Nasca para que poderes invasores se apropien de ella.

Los eventos y procesos que tomaron lugar en Cahuachi crearon una economía ritual y congregaron grandes cantidades de personas en contextos ceremoniales extraordinarios, los cuales posiblemente requirieron la producción de notables cantidades de bienes materiales, como cerámica, alimentos, y estructuras arquitectónicas.

Culminando en el Horizonte Temprano, el modelo de integración social desarrollado en la región sur de Nazca, en el centro ceremonial de Cahuachi, tomó una importancia primordial y así, la mina Primavera se convirtió también en una fuente de abastecimiento de substancias importantes para la vida ceremonial.

Considerando la tremenda riqueza mineral de los cerros y los valles andinos, no es muy probable que la mina Primavera haya sido la única fuente de hematita abasteciendo Cahuachi. Estudios recientes en la Costa Sur han descubierto evidencia de minería prehispánica en las regiones de Nazca e Ica (Eerkens et al. 2009; Stöllner 2009; Van Gijseghem et al. 2011, 2013; Reindel et al. 2013). Aun así, dado el carácter extractivo de la minería, muchos de estos contextos han sido alterados de tal manera que hoy en día no se puede esperar encontrar un contexto primario con mucha frecuencia. Desde este punto de vista, mina Primavera constituye una especie de accidente histórico, habiendo sido preservada con relativa integridad por un milenio y medio, permitiéndonos hoy un vistazo excepcional a las condiciones bajo las cuales ocurrieron los primeros pasos en la producción de bienes suntuarios: la manera en la cual dichos materiales fueron obtenidos, además de lo que esta adquisición representó para los agentes involucrados. Finalmente, al proveernos con mayor documentación de un modo de producción ritual, nos permite entender con mayor plenitud el funcionamiento de las sociedades de la Costa Sur.

\section{REFERENCIAS}

Bachir Bacha, A. y O. Llanos

2006 El gran templo del centro ceremonial de Cahuachi, Nazca, Perú, Dimensión Antropológica 38, 49-86.

Beresford-Jones, D., S. Arce, O.Q. Whaley y A. Chepstow-Lusty

2009 The role of Prosopis in ecological and landscape change in the Samaca Basin, lower Ica, Valley, south coast Peru from the Early Horizon to the Late Intermediate Period, Latin American Antiquity 20(2), 303-332. https://doi.org/10.1017/S1045663500002650

Bird, J.

1979 The «copper man»: A prehistoric miner and his tools from northern Chile, en: E. P. Benson (ed.), Pre-Columbian metallurgy of South America, 105-132, Dumbarton Oaks, Washington, D.C.

Bloxam, E.

2011 Ancient quarries in mind: Pathways to a more accessible significance, World Archaeology 43 (2), 149-166. https://doi.org/10.1080/00438243.2011.579481

Bonavia, D.

1959 Una pintura mural de Pañamarca, Valle de Nepeña, Arqueológicas 5.

1985 Mural painting in ancient Peru, University of Indiana Press, Bloomington. 


\section{Bouysse-Cassagne, $\mathrm{T}$.}

2005 Las minas del centro-sur andino, los cultos prehispanicos y los cultos cristianos, Bulletin de l'Institut Français d'Études Andines 34 (3), 443-462. https://doi.org/10.4000/bifea.4988

Brady, J.E. y D. Rissolo

2006 A reappraisal of Ancient Maya Cave Mining, Journal of Archaeological Research 62(4), 471-490. https:// doi.org/10.3998/jar.0521004.0062.402

Cobo, B.

1890-5 Historia del Nuevo Mundo, E. Rasco, Sevilla.

[1653]

Cook, A.

1984- The Middle Horizon ceramic offerings at Conchopata, Nawpa Pacha 22-23, 49-90.

1985 https://doi.org/10.1179/naw.1984.22-23.1.002

\section{Craddock, B.R., C.R. Cartwright, P.T. Craddock y W.B. Bray}

2003 Hafted stone mining hammer from Chuquicamata, Chile, en: P. Craddock y J. Lang (eds.), Mining and metal production through the ages, 52-68, The British Museum Press, London.

\section{Dawson, L.E.}

1964 Slip casting: A ceramic technique invented in ancient Peru, Nawpa Pacha 2, 107-112. https://doi. org/10.1179/naw.1964.2.1.002

\section{Edwards, M.}

2010 Archaeological investigations at Pataraya: A Wari outpost in the Nasca Valley of Southern Peru, tesis de doctorado, Department of Anthropology, University of California, Santa Barbara.

2013 The configuration of built space at Pataraya and Wari provincial administration in Nasca, Journal of Anthropological Archaeology 32, 565-576. https://doi.org/10.1016/j.jaa.2013.09.004

Eerkens, J., K.J. Vaughn y M. Linares

2009 Pre-Inca mining in the southern Nasca Region, Peru, Antiquity 83, 738-750. https://doi.org/10.1017/ S0003598X00098951

Eerkens, J., G.H. Barford, K.J. Vaughn, P.R. Williams y C.E. Lesher

2014 Iron isotope analysis of red and black pigments on pottery in Nasca, Peru, Archaeological and Anthropological Science 6, 241-254. https://doi.org/10.1007/s12520-013-0151-6

Eitel, B., S. Hecht, B. Machtle, G. Schukraft, A. Kadereit, G.A. Wagner, R. Kromer, I. Unkel y M. Reindel

2005 Geoarchaeological evidence from desert loess in the Nazca-Palpa region, Southern Peru: Paleoenvironmental changes and their impact on pre-Columbian cultures, Archaeometry 47 (1),137-158. https://doi.org/10.1111/j.1475-4754.2005.00193.x

\section{Glowacki, M. y M. Malpass}

2003 Water, huacas, and ancestor worship: Traces of a sacred Wari landscape, Latin American Antiquity 14 (4), 431-448. https://doi.org/10.2307/3557577

\section{Gorman, A., J. Eerkens y K.J. Vaughn}

2013 Electron microprobe analysis of Nasca polychrome ceramic pigments, ponencia presentada a la 53rd Annual meeting of the Institute of Andean Studies, Berkeley.

Gose, P.

1986 Sacrifice and the commodity form in the Andes, Man 21 (2), 296-310. https://doi.org/10.2307/2803161

1993 Segmentary state formation and the ritual control of water under the Incas, Comparative Studies in Society and History 35 (3), 480-514. https://doi.org/10.1017/S0010417500018557

Greene, S. E.

2002 Sacred sites and the colonial encounter: A history of meaning and memory in Ghana, Indiana University Press, Bloomington.

Gruszcynska-Ziolkowska, A. y T. Prusik

2000 Tocando los números: las antaras nasquenses desde una perspectiva acústica, Estudios Latinoamericanos 20, 66-82. 
Heaberli, J.

1979 Twelve Nasca panpipes: a study, Ethnomusicology 23 (1), 57-74. https://doi.org/10.2307/851338

Harris, $\mathrm{O}$.

2000 To make the earth bear fruit: essays on fertility, work and gender in highland Bolivia, Institute of Latin American Studies, London.

\section{Kantner, J. y K. J. Vaughn}

2012 Pilgrimage as costly signal: Religiously motivated cooperation in Chaco and Nasca, Journal of Anthropological Archaeology 31(1), 66-82. https://doi.org/10.1016/j.jaa.2011.10.003

\section{Kerchusky, $S$.}

2013 ms. Mina primavera textile and cordage report, manuscrito en posesión de los autores.

Kroeber, A. y D. Collier

1998 The archaeology and pottery of Nazca, Peru: Alfred L. Kroeber's 1926 Expedition, AltaMira Press, Walnut Creek.

Llagostera, A., R. Weisner, G. Castillo, M. Cervellino y M. A. Costa

2000 El Complejo Huentelauquén bajo una perspectiva macrospacial y multidisciplinaria, Contribución Arqueológica 5:¿, 461-480.

Menzel, D., J.H. Rowe y L.E. Dawson

1964 The Paracas pottery of Ica: A study in style and time, University of California Press, University of California Publications in American Archaeology and Ethnology, Berkeley/Los Angeles.

Montoya, M., G. Wilfredo y J. Caidas

1994 Geología de los cuadrángulos de lomitas, Palpa, Nasca, y Puquio, Boletin 53, Instituto Geológico, Minero y Metalúrgico, Lima.

Murúa, M.

1925 Historia de los Incas, reyes de Perú: Colección de libros y documentos referentes a la historia del Perú, tomo V, Sanmartí, Lima.

Nash, J.

1972 Devil in Bolivia’s nationalized tin mines, Science and Society 36, 221-233.

Olsen, D. A.

2002 Music of El Dorado: The ethnomusicology of ancient south American cultures, University Press of Florida, Gainseville.

Orefici, G.

2011 Cahuachi: capital teocrática Nasca, Fondo Editorial Universidad de San Martin de Porres, Lima.

Orefici, G. y A. Drusini

2003 Nasca: hipótesis y evidencias de su desarrollo cultural, Centro Italiano Studi e Ricerche Archeologiche Precolombiane, Brescia.

Petersen, G.

2010 Mining and metallurgy in ancient Perú [traducción de W. E. Brooks], Boulder: The Geological Society of America, Special Paper 467, Boulder.

Phipps, E.J.S.

1989 Cahuachi textiles in the W.D. Strong collection: Cultural transition in the Nasca Valley, Peru, tesis de doctorado, Columbia University, New York.

Pillsbury, J.

1996 The thorny oyster and the origins of empire: Implications of recently uncovered spondylus imagery from Chan Chan, Peru, Latin American Antiquity 7 (4), 313-340. https://doi.org/10.2307/972262

Prieto, G., V. Wright, R.L. Burger, C. Cooke, E.L. Zeballos-Velasquez, A. Watanabe, M.R. Suchomel y L. Suescun 2016 The source, processing and use of red pigment based on hematite and cinnabar at Gramalote, an early Initial Period (1500-1200 cal. B.C.) maritime community, north coast of Peru, Journal of Archaeological Science 5, 45-60. https://doi.org/10.1016/j.jasrep.2015.10.026 
Proulx, D.

2006 A sourcebook of Nasca ceramic iconography, University of Iowa Press, Iowa City.

Reindel, M.

2009 Life at the edge of the desert: Archaeological reconstruction of the settlement history in the Valleys of Palpa, Peru, en: M. Reindel y G. Wagner (eds.), New technologies for archaeology: Multidisciplinary investigations in Palpa and Nasca, Peru, 439-461, Springer-Verlag, Berlin/Heidelberg. https://doi.org/ 10.1007/978-3-540-87438-6_25

\section{Reindel, M., T. Stollner y B. Grafingholt}

2013 Mining archaeology in the Nasca and Palpa region, south coast of Peru, en N. Tripcevich y K.J. Vaughn (eds.), Mining and quarrying in the ancient Andes: Sociopolitical, economic, and symbolic dimensions, 299-324, Springer, New York. https://doi.org/10.1007/978-1-4614-5200-3_14

Ríos Valladares, P.

2007 El sector CAH 04, Y8 - EXP 108: las funciones de la plaza al este de la gran pirámide en los complejos ceremoniales de Cahuachi (Nazca), Período Intermedio Temprano, tesis de licenciatura, Pontificia Universidad Católica del Perú, Lima.

Salazar, D., D. Morata, V. Castro, G. Manríquez y J. Guendon

2011 Early evidence (ca. 12,000 BP) for iron oxide mining on the Pacific coast of South America, Current Anthropology 52(3), 463-475. https://doi.org/10.1086/659426

Scalise, R. y V. Di Prado

2006 Early use of ochre in the Pampean Region of Argentina, Current Research in the Pleistocene 23, 66-68.

Schreiber, K.

2005 Sacred landscapes and imperial ideologies: The Wari Empire in Sondondo, Peru, en: K.J. Vaughn, C.A. Conlee, y D. Ogburn (eds.), The foundations of power in the prehispanic Andes, 113-130, Archaeological Papers of the American Anthropological Association, Washington, D.C.

Shimada, I.

1994 Pre-hispanic metallurgy and mining in the Andes: Recent advances and future tasks, en A.C. Craig y R.C. West (eds.), Quest of mineral wealth: Aboriginal and colonial mining and metallurgy in Spanish America, 37-74, Geoscience and Man 33, Louisiana State University, Baton Rouge.

Silva, J. y D. Bahamondes

1969 Investigaciones Arqueológicas en Taltal, Rehue 2, 7-25.

Silverman, $\mathrm{H}$.

1993 Cahuachi in the ancient Nasca world, University of Iowa Press, Iowa City.

2002 Nasca settlement and society on the hundredth anniversary of Uhle's discovery of the Nasca style, en: H. Silverman y W. Isbell (eds.), Andean archaeology I: Variations in sociopolitical organization, 121-158, Kluwer Academic/Plenum Press, New York. https://doi.org/10.1007/978-1-4615-0639-3_5

Spielmann, K.A.

2002 Feasting, craft specialization, and the ritual mode of production in small-scale societies, American Anthropologist 104 (1), 195-207. https://doi.org/10.1525/aa.2002.104.1.195

Stöllner, T.

2009 Gold in southern Peru? Perspectives of research into mining archaeology, en: M. Reindel y G. Wagner (eds.), New technologies for archaeology: Multidisciplinary investigations in Palpa and Nasca, Peru, 393-407, Springer-Verlag, Berlin/Heidelberg. https://doi.org/10.1007/978-3-540-87438-6_23

Ünkel, I., B. Kromer, M. Reindel, L. Wacker y G. Wagner

2007 A chronology of the pre-Columbian Paracas and Nasca cultures in South Peru based on AMS 14 C Dating, Radiocarbon 49 (2), 551-564. https://doi.org/10.1017/S0033822200042466

Ünkel, I., M. Reindel, J. Gorbahn, J. Isla Cuadrado, B. Kromer y V. Sossna

2012 A Comprehensive numerical chronology for the pre-Columbian cultures of the Palpa Valleys, South Coast of Peru, Journal of Archaeological Science 39, 2294-2303. https://doi.org/10.1016/j.jas.2012.02.021 
Van Gijseghem, H.

2006 A frontier perspective on Paracas society and Nasca ethnogenesis, Latin American Antiquity 17 (4), 419-444. https://doi.org/10.2307/25063066

2013 Our children might be strangers: Frontier migration and the meeting of cultures across generations, Archaeological Review from Cambridge 28(1),169-189.

Van Gijseghem, H. y K.J. Vaughn

2008 Regional integration and the built environment in middle range societies: Paracas and Early Nasca houses and communities, Journal of Anthropological Archaeology 27, 111-130. https://doi.org/10.1016/j. jaa.2007.11.002

Van Gijseghem, H., K.J. Vaughn, V.H. Whalen, M. Linares y J. Olano

2011 Prehispanic mining in South America: New data from the Upper Ica Valley, Peru, Antiquity 85 (328).

2013 Economic, social, and ritual aspects of copper mining in ancient Peru: An Upper Ica Valley case study, en: N. Tripcevich y K.J. Vaughn (eds.), Mining and quarrying in the ancient Andes, 275-298, Springer, New York. https://doi.org/10.1007/978-1-4614-5200-3_13

Vaughn, K.J.

2004 Households, crafts, and feasting in the ancient Andes: The village context of Early Nasca craft consumption, Latin American Antiquity 15 (1), 61-88. https://doi.org/10.2307/4141564

2005 Crafts and the materialization of chiefly power in Nasca, en: K.J Vaughn, C.A. Conlee y D. Ogburn (eds.), The foundations of power in the prehispanic Andes, 113-130, Archaeological papers of the American Anthropological Association 14, Washington, D.C. https://doi.org/10.1525/ap3a.2004.14.113

2009 The ancient andean village: Marcaya in prehispanic Nasca, University of Arizona Press, Tucson.

Vaughn, K.J., C.A. Conlee, H. Neff y K.J. Schreiber

2006 Ceramic production in ancient Nasca: Provenance analysis of pottery from the Early Nasca and Tiza cultures through INAA, Journal of Archaeological Science 33(5), 681-689. https://doi.org/10.1016/j. jas.2005.10.002

Vaughn, K.J., J. Eerkens, M. Linares y M. Edwards

2007 Hematite mining in the ancient Americas: Mina Primavera, a 2,000 year old Peruvian mine, JOM: The Journal of The Minerals, Metals, \& Materials Society 59, 21-25. https://doi.org/10.1007/s11837007-0145-x

Vaughn, K.J. y H. Neff

2004 Tracing the clay source of Nasca polychrome pottery: Results from a preliminary raw material survey, Journal of Archaeological Science 31(11), 1577-1586. https://doi.org/10.1016/j.jas.2004.03.021

Vaughn, K.J., y N. Tripcevich

2013 An Introduction to mining and quarrying in the ancient Andes: Sociopolitical, economic, and symbolic dimensions, en: N. Tripcevich y K.J Vaughn (eds.), Mining and quarrying in the ancient Andes, 3-22, Springer, New York. https://doi.org/10.1007/978-1-4614-5200-3_1

Vaughn, K.J. y H. Van Gijseghem

2007 A compositional perspective on the origins of the Nasca cult at Cahuachi, Journal of Archaeological Research 34(5), 814-822. Nasca cult at Cahuachi, Journal of Archaeological Research 34(5), 814-822. https://doi.org/10.1016/j.jas.2006.08.008

Vaughn, K.J., H. Van Gijseghem, M. Linares y J. Eerkens

2013a Minería de hematita en la Costa Sur del Perú: Investigaciones arqueológicas en la mina Primavera, Chungará 45 (1), 131-142. https://doi.org/10.4067/S0717-73562013000100006

Vaughn, K.J., H. Van Gijseghem, V.H. Whalen, J. Eerkens y M. Linares Grados

2013b The organization of mining in Nasca DURING the Early Intermediate Period: Recent evidence from mina Primavera, en: N. Tripcevich y K.J Vaughn (eds.), Mining and quarrying in the ancient Andes, 157-182, Springer, New York. https://doi.org/10.1007/978-1-4614-5200-3_8

Wernke, S. A.

2012 Spatial network analysis of a terminal prehispanic and Early Colonial settlement in highland Peru, Journal of Archaeological Science 39(4),1111-1122. https://doi.org/10.1016/j.jas.2011.12.014 
Whitehouse, R.D.

1992 Underground religion: Cult and culture in prehistoric Italy, Specialist Studies on Italy 1, Accordia Research Centre, University of London, London.

Williams, P.R. y D.J. Nash

2006 Sighting the Apu: A GIS analysis of Wari Imperialism and THE WORSHIP OF MOUNTAIN PEAKS, World Archaeology 38 (3), 455-468. https://doi.org/10.1080/00438240600813491

Wright, V.

2010 Pigmentos y tecnología artística mochicas: Una nueva aproximación en la comprensión de la organización social, Bulletin de l'Institut Français d'Études Andines 39 (2), 229-330. https://doi.org/10.4000/ bifea. 1950

Yacovleff, E. y J.C. Muelle

1934 Un fardo funerario de Paracas, Revista del Museo Nacional 3, 63-153.

Recepción: 4/VI/2018

Aceptación: 17/VII/2018 